\title{
EDITORIAL
}

\section{Aspectos ético-médicos del aborto}

Veinte años de estudio y reflexión sobre el aborto inducido, sus causas y consecuencias, sus implicaciones de carácter ético y sobre los conflictos que el tema suscita, culminan para mi en este simposio sobre Enfoque Constitucional y Legal del aborto que en buena hora la Sociedad Colombiana de Obstetricia y Ginecologia ha convocado.

Los aspectos médicos del aborto clandestino inseguro y de alto riesgo están ampliamente documentados en la literatura médica colombiana y las características del aborto seguro tal como se practica hoy en la mayor parte del mundo, han quedado registradas también en innumerables articulos en las revistas más autorizadas de la literatura médica universal (1).

Lo novedoso en relación con el aborto, es el reconocimiento creciente del embarazo indeseado como origen y precursor del aborto inducido y de que mas allá de lo puramente médico, se asocian al aborto una serie de aspectos no médicos que deben tenerse en cuenta.

El camino hacia una nueva perspectiva del aborto está hoy más claro a raiz de la reunión convocada en marzo de 1997 por la Federación Internacional de Ginecologia y Obstetricia (FIGO) y la Organización Mundial de la Salud (OMS) sobre la responsabilidad que cabe a los especialistas en Obstetricia y Ginecología en la solución de la compleja problemática-NO MEDICA-asociada al aborto (2).

Es en esa nueva perspectiva del aborto, que sin ser eticista pero si basado en la reflexión, el análisis, en múltiples lecturas y como participante en diversos foros sobre el tema, me atrevo a explorar en esta presentación sobre aspectos ético-médicos del aborto.

Considero que el aborto es un tema de múltiples facetas que interactúan con gran complejidad en la sociedad contemporánea por lo tanto, y sin pretender ser exhaustivo, me limitaré a formular una serie de interrogantes que buscan despertar en el obstetra-ginecólogo su interés por el análisis de un problema para el cual, cada uno y dentro de su propia conciencia, debe tratar de encontrar las respuestas adecuadas.

La palabra ETICA se deriva del griego "ethos" que significa costumbres ha sido objeto de múltiples definiciones, entre las que escojo por personal preferencia aquella que a nivel individual entiende por ETICA "la exigencia que se hace a si mismo un individuo, de someter su conducta diaria a un criterio o valor moral referido a la dignidad humana".

Tratándose del aborto, desde la perspectiva del médico considero también adecuado el aproximarnos a él desde la bioética entre cuyas principales caracteristicas citadas por Alfonso Llano S.J. (3) destaco, que la biótica es ante todo ética, que nace en un ambiente cientifico, que no es confesional, surge de un ambiente interdisciplinario y no se trata de una ciencia ya hecha. En razón de lo anterior me refériré indistintamente tanto a la ética como a la bioética.

La ética no es como algunos pudieran pensar una ciencia teórica que se basa en disquisiciones totalmente alejadas de la realidad. En nuestro caso la ética médica es una disciplina en la cual se desarrollan destrezas útiles para la toma de decisiones que nos ayuden frente a una situación médica que consideramos difícil, concepto expresado por el ginecólogo y eticista Francisco Abel S.J. 
cuando afirma que "La dimensión bioética ha de tomar en consideración los aspectos sociales, politicos, psicológicos y legales. La metodología ha de permitir una razonable decisión específica y clara en una situación determinada" (4).

La ética trata de

= Identificar problemas éticos subyacentes

= analizar las opciones disponibles

= seleccionar una entre varias alternativas

= justificar la selección hecha

La ética reconoce que no siempre hay una respuesta absoluta para cada cuestión moral.

Por lo tanto, al analizar los diversos aspectos ético-médicos del aborto, será necesarioformularnos a nosotros mismos una serie de preguntas que nos permitan conocer las circunstancias que llevan a las mujeres a abortar, circunstancias que solamente cada una de ellas conoce en todos sus detalles y sobre las cuales, podriamos pronunciar un juicio ético solamente en cada caso particular:

* ¿Cuál es la razón por la cual la mujer quiso o quiere abortar?

* ¿Hay alguna alternativa que podamos sugerir u ofrecer a esa mujer concreta que le permita, según su criterio, evitar el aborto?

* ¿Cuál es la edad gestacional del embarazo que ella desea interrumpir?

* ¿Cuáles son nuestros valores frente a la sexualidad, la anticoncepción, el embarazo indeseado y el aborto?

La ETICA no es eterna ni inmutable; es por el contrario, una teoria siempre cambiante en un mundo donde el pluralismo de ideas, culturas, religiones, politicas y aún de filosofías, es cada vez mayor tal como lo expresa Marciano Vidal (5), cuando citando a Sporken afirma: "Las intuiciones éticas que se nos han trasmitido aparecen hoy dia debido a la mutación de nuestra idea del hombre $y$ del mundo, sometidas a una profunda revisión crítica. Esto ha de decirse aún con más énfasis en lo que respecta a la ética médica, dado que la investigación médica y la asistencia facultativa se encuentran en un desarrollo progresivo extraordinariamente rápido".

Error frecuente en relación con la ETICA es confundirla con la religión o asimilarla a la ley. Mientras la ética es anterior a las religiones hoy dia existentes, no todo lo que es ético es legal y no todo lo que es o ha sido legal es necesariamente ético.

Los problemas éticos que se plantean al médico moderno son múltiples y el aborto es solamente uno de ellos:

- Diagnóstico prenatal de anormalidad fetal

- Inseminación artificial

- Fertilización in vitro

- Investigación en embriones

- Embrión extrauterino

- Congelación de embriones

- Eliminación de embriones

- Escogencia del sexo fetal

- Terapiafetal

- Cirugía fetal 
- Transplante de órganos fetales

- Utero sustituto

- Aborto inducido

Al aproximarnos al aborto es de crucial importancia en la comprensión integral del tema, asi como para poder adoptar una posición y actitud profesional y ética, considerar otras facetas NO estrictamente médicas que, tomando de una presentación anterior (6) menciono a continuación y solo a manera de ejemplo, unos pocos de los muchos interrogantes que el médico, frente a la mujer que aborta debe tratar de responder con sensibilidad, respeto, bondad, tolerancia y justicia.

\section{¿Por qué y contra su voluntad, quedan embarazadas las mujeres?}

- Relaciones sexuales sin protección anticonceptiva

- Uso irregular de los métodos

- Fallas de los métodos

- Necesidad de comprobar su propia fertilidad

- Intención de comprometer al novio o pareja.

- Presión familiar para tener un hijo

- Exigencia del esposo o compañero.

- Violencia y abuso sexual

Todos los aspectos anteriores son de innegable ocurrencia y comienzan a explicarnos por qué, a pesar de la anticoncepción ampliamente disponible, muchas mujeres continúan quedando embarazadas sin quererlo.

\section{¿Por qué el rechazo al embarazo?}

Las razones posibles son múltiples pero es sólo la mujer, cada mujer, quien conoce aquellas que en su caso particular la obligan a rechazar un embarazo.

- Implica interrupción de estudios

- Rechazo de la pareja o miedo a perderla si se continúa el embarazo

- Rechazo de la familia

- Temor al escándalo socio - familiar

- Rechazo laboral

- Por ser inoportuno e imponer cambios radicales de sus planes de vida

- Embarazos y partos previos dolorosos, o incapacitantes.

- Infidelidad real o aparente de la pareja

- Inseguridad por fragilidad de la relación de la pareja

- Ya tiene el número de hijos que desea

- No desea ningún hijo

- Recursos económicos insuficientes

- Mala salud

- Consejo de su médico (edad, iatrogenia por fármacos o factores genéticos)

- No sentirse emocionalmente preparada para la crianza.

¿Con qué derecho o autoridad moral podemos como médicos, jueces o sacerdotes, casi siempre hombres y por lo tanto sin riesgo de enfrentar en carne propia un embarazo, juzgar si las razones son válidas o inaceptables? 


\section{¿Qué alternativas contempla la mujer embarazada que rechaza su embarazo?}

- Continuar y dar a luz un hijo indeseado.

- Dar su hijo en adopción.

- Abandonar su hogar

- Suicidarse

- Abortar

Obviamente ninguna de ellas es atractiva y la mujer enfrentada al problema tendrá que decidirse por aquella que en su concepto sea la menos mala de las soluciones.

Es innegable que para el médico, quizás con mayor énfasis para el obstetra-ginecólogo el aborto representa un enorme conflicto interior; que se puede presentar en los niveles personal o interno, institucional, familiar, social o público.

En este conflicto se mezclan múltiples aspectos: La vida y el ser persona, el embarazo indeseado, la salud publica, la salud individual, el futuro del hijo indeseado a corto, mediano y largo plazo, las doctrinas de las diversas religiones y la ley, temas sobre los cuales el profesional de la salud por lo general tiene información muy parcial o ninguna, tanto de lo que ocurre en Colombia como en el resto del mundo.

El plantear el aborto sobre bases teóricas, sobre principios "absolutos" y tratar de definir si el aborto es bueno o malo no conduce absolutamente a nada. Es indispensable analizar cada caso en particular, reconociendo que el aborto representa un gran dilema ético que rechaza una definición simple.

Al considerar los aspectos ético-médicos del aborto debemos reconocer que el tema plantea un conflicto de valores que debe resolverse de alguna manera, pues en él se enfrentan por una parte la vida del feto o del embrión y por la otra, la vida de la mujer.

En un gran número de países con alta proporción de población católica como los Estados Unidos de Norte América y muchos de Europa donde el aborto no está penalizado por la ley se ha desatado una agitada polémica centrada sobre el valor relativo de la vida del feto frente a la vida de la madre, discusión donde las opiniones se polarizan hasta el extremo de afirmar que la vida en gestación tiene exactamente el mismo valor y los mismos derechos que la madre y en el campo opuesto en aceptar. sin cuestionamiento alguno el aborto inducido hasta el tercer trimestre del embarazo.

Es obvio que la radicalización de opiniones asi expresada no puede llevar a ninguna conclusión y es asi como teólogos modernos, organizaciones científicas y profesionales de diversas disciplinas. en un esfuerzo por llegar a un acuerdo, aceptan con Clifford Grobestein, profesor emérito de Biología de la Universidad de California y católico, que el embrión a partir de los días 12 a 15 de la gestación es un ser vivo individual y único con la potencialidad de crecer y llegar a ser una persona con todos los derechos.

Que el feto a partir de la octava semana de embarazo, es un ser que depende totalmente de la madre pero que a medida que crece dentro del útero, va adquiriendo progresivamente derechos que sin embargo no pueden equipararse a los derechos de la madre.

Que el feto al llegar a la edad gestacional a partir de la cual podría continuar viviendo si estuviera separado de su madre, comienza desde el punto de vista médico a ser un paciente digno de recibir todos los recursos disponibles de la medicina moderna que le permitan sobrevivir frente a cualquier contingencia o enfermedad; pero que solamente a partir de la semana 26 del embarazo, cuando ya se han establecido en el cerebro fetal las conexiones nerviosas que pudieran permitir la toma de su propia conciencia y la capacidad de percibir el dolor, solamente a partir de esa época y no antes, será posible que el feto se convierta en persona (7). 
Mientras el carácter juridico de persona se adquiere en la casi totalidad de las legislaciones del mundo a partir del nacimiento, la discusión moral y religiosa sobre si es o no persona, es prácticamente imposible de resolver y queda a la conciencia de cada uno el formarse su propia escala de valores en relación a tan delicado asunto.

Para Chervenak y McCullough cientificos del Centro Médico de Cornell y de la Universidad de Baylor (8) apoyados por la Sociedad Norte Americana de Psicología, la pregunta fundamental de la ETICA OBSTETRICA, en esta época de tecnología cada vez más avanzada, es: ¿cuándo es el feto, lo mismo que la mujer embarazada, un paciente a quien se debe proteger y respetar en igual forma que a la madre?

Para los autores mencionados, el aborto de un feto antes de que éste sea viable no representa violación alguna de los principios de la ética obstétrica secular, mientras que el aborto de fetos viables sería una flagrante transgresión del principio médico de beneficencia que éstos nos merecen.

El embarazo no deseado $\boldsymbol{E S}$ el origen del aborto, tema del que prefeririamos no hablar y que por los estigmas que nuestra cultura le ha asignado al hacerlo ilegal y por lo tanto clandestino, peligroso y susceptible de explotación, no constituye "tema de buen recibo" sino asunto que gobiernos, religiones, grupos profesionales y la opinión pública en general, ignoran o prefieren evadir.

Como profesionales al servicio de la mujer, los médicos no podemos ignorarlo y pese a las reacciones que el mismo nos despierta, tenemos la obligación moral y la responsabilidad ética de enfrentarnos a esa realidad puesto que es a través de su análisis que seremos capaces de "encontrar un nuevo camino en un diálogo abierto a la ciencia respetuoso con la tradición pero sin ser esclavizado por ella" (9).

Definir nuestra posición y nuestra actitud frente al embarazo no deseado y al aborto, no es fácil y si bien al hacerlo debemos tener en cuenta principios consagrados por la tradición, por la cultura y por el medio en que vivimos, es primordial utilizar la razón y tener en cuenta que lo que es MORAL y ETICO se fundamenta en la realidad.

Tengamos en cuenta que el embarazo no deseado y el aborto no se dan en abstracto sino en personas concretas y que estamos frente a una experiencia individual y única de cada mujer directamente involucrada.

Acerquemos al tema con humildad, con conocimiento y claridad mental. Mantengámonos informados y en permanente espíritu de reflexión y estudio, sin tratar de imponer nuestra ética sobre los demás y pongamos al servicio de las mujeres toda nuestra capacidad profesional y nuestro compromiso de contribuir plenamente a su salud y bienestar.

\section{BIBLIOGRAFIA}

1. Council on Scientific Affairs, American Medical Association Induced Termination of Pregnancy Before and After Roe $v$ Wade Trends in the Mortality and Morbidity of Women JAMA 1992; 268(22).

2. Grupo de Trabajo FIGO / OMS. "Aborto: Una Responsabilidad Profesional de los Obstetras y Ginecólogos". Relatorio Final. CEMICAMP, Campinas, SP, Brasil marzo 1997

3. Alfonso Llano S.J. Qué es la Bioética: Lecturas Escogidas, Centro Nacional de Bioética (página 19 y siguientes). Bogotá 1993.

4. Francisco Abel SJ.Bioética: Un nuevo concepto y una nueva responsabilidad. Qué es la Bioética: Lecturas Escogidas, Centro Nacional de Bioética (página 19 y siguientes) Bogotá 1993.

5. M. Vidal y J. Elizari. La Bioética. Nuevo Diccionario de Teología Moral. 1992; 69-70.

6. Jorge Villarreal. Aspectos No médicos del Aborto. Congreso Extraordinario de Obstetricia y Ginecologia. Lima, octubre 27 de 1997.

7. Clifford Grobestein. Science and the Unborn: Choosing Human Futures Chapter 7 Reaching Decisions on Status for the Unborn 1988; $132-156$.

8. Chervenak Frank A.M. D. y McCullough Laurence B. PhD. Does obstetric ethics have any role in the obstetricians response to the abortion controversy? Am J Obs-Gynec 1990; 163: 1425-1429.

9. Francisco Abel S.J. Bioétlca: Un Nuevo concepto y una nueva responsabilidad Tomado de: Qué es la Bioética. Lecturas escogidas. Centro Nacional de Bioética (página 46) Bogotá 1993. 